\section{Australia backs off CSIRO merger with nuclear body}

Sydney. Members of the governing board of Australia's Nuclear Science and Technology Organisation (ANSTO), the body which runs two research reactors outside Sydney, have agreed to resign following the failure of an attempt to merge it with the Commonwealth Scientific and Industrial Research Organisation (CSIRO).

Their resignations will allow for the implementation of a compromise arrangement under which ANSTO's board will be reconstituted to include a number of CSIRO nominees. The move is being seen as a way of encouraging closer collaboration between the two organizations.

The original suggestion of a full merger between the two had been proposed to the government by Chris Schacht, the minister for science and small business, as a way of achieving this goal and also saving money. However this proposal was rejected by the Federal cabinet of ministers. Some members are thought to have been unconvinced by Schacht's argument that the merger of the two agencies would have saved Aus $\$ 25$ million (US\$38 million) a year.

Defending the government's decision, Schacht argued that Australia's Greens and other minority parties, who hold a significant voting bloc in the Senate, would have delayed the merger legislation because of general opposition to all nuclear activities.

Behind the decision to reconstitute the ANSTO board lie reports of conflict between Schacht and the board, which will continue to function in a 'caretaker' role until Christmas, and is headed by Richard Collins, professor of applied physics at Sydney University.

Schacht is reported to have accused the board of bad management. Such charges have been fanned, for example, by recent problems with the installation of a supercomputer, the subject of an audit report soon to be released by the government.

ANSTO and its supporters, however, argue that occasional mistakes are inevitable when an organization undergoes largescale change, as the nuclear body has been doing over the past few years. They also counter Schacht's charges with accusations of excessive ministerial interference in the management of the organization.

Schacht says that the new ANSTO board will review the operations of the organization to ensure that the government's objectives - including developing closer links with CSIRO - are being met. The arrangements will be reviewed in two years, says Schacht, warning that unless the government's objectives are achieved, further consideration will be given to merging the two organizations.

Mark Lawson

\title{
Spanish physicists are spoilt for choice of accelerators
}

Barcelona. The Spanish government has opened discussions with three regional governments over how much support it is prepared to provide for their separate plans to build particle accelerators. But the plans have been criticized as being insufficiently coordinated, driven by political motives, and a drain on scarce financial resources.

The respective plans are for a large synchotron in Barcelona, the capital of the northern autonomous region of Catalonia; a smaller synchotron in Seville, in the southern region of Andalusia; and for a third accelerator - possibly linear - in Madrid. Each has sprung from a desire by the respective regions to attract the biggest slice of the national science budget.

At the official opening of Cartuja '93, Spain's new science park occupying the

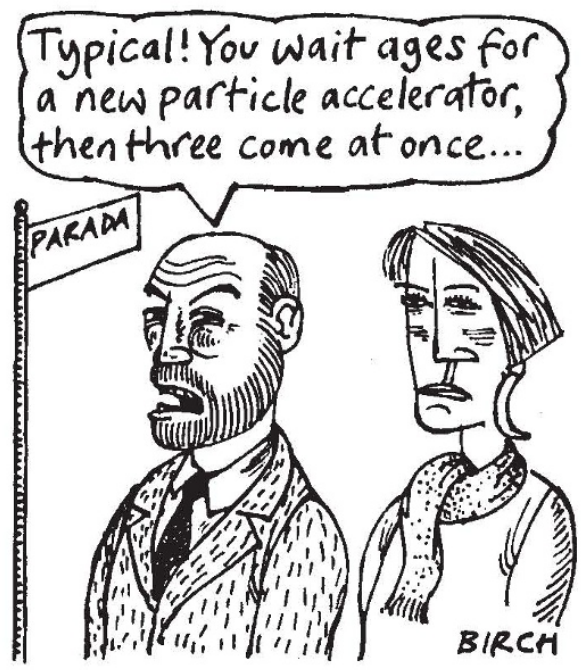

groups of Expo '92 in Seville, Elias Fereres, state secretary for universities and research, defended the government's decision to back all three projects. "We want to guarantee access to all Spanish researchers interested in using these machines," he said.

Originally, Spain had hoped to build a tau-charm factory. However these hopes crashed last December when the European particle physics laboratory, CERN, refused to support the proposal. Fereres reached agreement in principle with Seville, Madrid and Barcelona to support instead a synchotron for Barcelona and a cyclotron for Seville, principally for medical purposes.

The news of plans for a synchotron in Andalucia, instead of the proposed cyclotron, has therefore taken scientists by surprise. Manuel Lozano, head of nuclear physics at the University of Seville, says that it would be a "disaster" if Catalonia and Andalucia ended up with the same sort of machine, which could not be justified in such a small scientific community.
"No-one knows where the terms got changed", says Lozano. The proposed machine would be housed at the Cartuja site, and is expected to cost up to Pts1 billion (\$7.5 million).

The Catalonian synchotron, already under construction in Barcelona, is estimated to cost Pts 11 billion. The $2 \mathrm{GeV}$ machine will probably be housed in a technology park near the city's Autonomous University, and has already encountered criticism.

First, the number of potential users may be too small to make it competitive. By the time the synchotron is complete at the beginning of the next century, Geneva's $6 \mathrm{GeV}$ European Synchotron Radiation Facility will be in full operation. So too will several other smaller accelerators.

Second, the money Catalonia is prepared to pay for the synchotron is more than the total sum the region has put into science and research since the death of Franco. Regional government officials justify this expenditure as stimulating industry and research. But many scientists are critical of this choice of priorities.

Meanwhile in Madrid, the autonomous government has rejected a previous plan to buy a smaller $(0.7 \mathrm{GeV})$, second-hand synchrotron in favour of a small linear accelerator, housed in the University of Madrid.

Last month, talks opened between central government and the local governments of Andalucia and Catalonia on how budgets for all of these accelerators should be shared between them. According to Fereres, funding will come from the central government through the national science plan. But none of the plan's agreed budget has been earmarked for this purpose.

The country already has one accelerator, which is not yet in operation, and whose schedule has also been disrupted by politics. In 1989, Lozano raised Pts 150 million from the European Commission to buy a small ion electrostatic tandem accelerator.

But Luis Oró, general secretary of the national science plan, persuaded Lozano to buy a bigger machine ( 4 million volts) for national use. The additional Pts 350 million required for this machine has also been provided by the commission.

The accelerator was built in the United States, and is ready for delivery. But it remains in storage. The central and regional governments have now decided that it should be housed at the Cartuja site, which is having difficulty in attracting permanent occupants, rather than in the grounds of the university, as originally planned. But the Cartuja building will not be ready for the accelerator until at least 1996.

Luis Angel Fernández Hermana 